\title{
What Lies behind the Concept of Customer Relationship Management? Discussing the Essence of CRM through a Phenomenological Approach
}

\author{
Cristiane Drebes Pedron * \\ E-mail address: cdpedron@iseg.utl.pt \\ Instituto Superior de Economia e Gestão - ISEG \\ Lisboa, Portugal.
}

\section{Amarolinda Zanela Saccol}

E-mail address: aczanela@unisinos.br

Universidade do Vale do Rio dos Sinos - UNISINOS

São Leopoldo, RS, Brazil.

\begin{abstract}
Several authors and consulting firms show statistics indicating that at least 50\% of all CRM projects fail. Some of them attempt to point out a list of factors in order to guarantee successful CRM implementation and application. However, few people (either academics or practitioners) attempt to discuss or consider the essence of the idea of CRM. The main goal of this exploratory research is to discuss the CRM essence through a phenomenological approach. This paper assumes that one of the main reasons for CRM failure is the lack of understanding about the true meaning and implication of practices for managing the relationship with customers. Therefore, we need to question the essence of CRM itself and discuss the very concept of relationship. We claim that the idea of CRM involves very serious issues about institutions, roles, power and ethical values that have to be considered. In this article, we attempt to analyze the essence of relationship, trying to go beyond the common meaning of CRM. As the main results of this paper, we offer a critical reflection related to the different faces and aspects of the CRM phenomenon, not only as a matter of IT applications, but also as a strategy and even as an organizational philosophy.
\end{abstract}

Key words: customer relationship management (CRM); organizational strategy; information and communication technologies (ICT); relationship marketing.

Received 25 January 2008; received in revised form 16 September 2008.

Copyright (C 2009 Brazilian Administration Review. All rights reserved, including rights for translation. Parts of this work may be quoted without prior knowledge on the condition that the source is identified.

\footnotetext{
* Corresponding author: Cristiane Drebes Pedron

ISEG - Rua do Quelhas, 6, Postal Code 1200-781, Lisboa, Portugal.
} 


\section{INTRODUCTION}

Customer Relationship Management [CRM] has recently become one of the most discussed issues in the Information Technology [IT] field. Following the path of Enterprise Resource Planning [ERP] implementations, CRM is now a buzzword, and many consulting firms have been profiting by selling this kind of solution, which promises to guarantee a competitive advantage by using IT to support a close relationship between an organization and its customers.

However, many companies that have adopted this solution have not obtained the return they had hoped for. Payne (2006, p. 20) shows that:

$69 \%$ of CRM projects have little impact on sales performance;

- Companies think that their CRM projects are significantly less successful than their consultants or suppliers;

70\% of CRM initiatives will fail over the next 18 months;

$60 \%$ per cent of CRM projects end in failure.

Attempting to explain these statistics, several authors (Boulding, Staelin, Ehret, \& Johnston, 2005; Newell, 2003; Ngai, 2005; Payne, 2006) point out some problems that lead to CRM failure, such as:

Lack of skills in building and using the new IT-based CRM systems;

- Inadequate investments, as many projects dramatically exceed their planned cost and sometimes even their scope;

- Poor data quality and quantity, mainly for companies that are at the early stage of CRM development;

. Failure to understand the business benefits - many managers perceive only the high cost of CRM adoption and fail to understand the potential financial benefits at the earlier stages of the CRM project;

. Lack of leadership and top management involvement;

- Inadequate measurement systems - sometimes organizations do not know exactly what they want from a CRM adoption;

. Cultural problems - many organizations need to change their main strategy (vision, objectives, etc.) to focus their efforts on customers.

These reasons for CRM failure provide some clues, but, in an attempt to understand why this type of technology has resulted in such a high level of failure, these elements need to be questioned, above all: What does CRM really stand for? There is a solution being sold, but for what sort of problem? What kind of phenomenon are companies and academics dealing with?

One of the assumptions of this article is that one of the main reasons for CRM failure is the lack of understanding about the true meaning and implication of practices for managing relationships with customers. This assumption includes the view that, in the market, CRM is now seen as a technological tool/issue, while it should be considered as a strategic and even a philosophical matter that stretches far beyond the IT arena. Therefore, questioning the essence of CRM itself and discussing the very concept of relationship is of paramount importance.

With this research focus, the main goal of the article is to discuss the CRM essence through a phenomenological approach (Ciborra, 2002; Dreyfus, 1994; Heidegger, 1962; Husserl, 1970; Introna 
\& Ilharco, 2004). As its main results, it is expected to invite both academics and practitioners to reflect on the different facets and aspects of the CRM phenomenon, not only as a matter of IT applications, but also as a strategy and even as an organizational philosophy. The study assumes that this type of reflective and critical view can help to better evaluate the objectives and expected outcomes of CRM projects.

In the academic field, the discussion helps to point out several assumptions and questions for future research, as indicated in the last section of this article.

In this paper the CRM phenomenon with a critical and dialectical view is being analyzed. Therefore, the next section presents the adopted methodology, according to the phenomenological approach. The rest of the article is developed as follows: in the next section the current definitions of CRM are also analyzed, and the meaning of relationship is explored and discussed; at the end, there is a final discussion pointing out implications for research and practice.

\section{Methodological APPROACH}

This study is exploratory and has adopted a phenomenological approach as a methodology for inquiry.

Phenomenology encourages us to back to the things themselves, it means, to approach phenomena that present themselves directly to us as conscious human beings, and attempt to understand their essences. It has at its centre "the initial recognition of essential intuition as the necessary condition for locating the experiential world that philosophers seek to understand" (Natanson, 1973, p. 25).

A phenomenon is what humans directly experience (Crotty, 1998; Myers, 2004). Once a person approaches a phenomenon and his/her initial understanding of it, in sequence the phenomenological method proposes to question what is usually take for granted. It proposes that (as best as one can) the prevailing understanding of the phenomenon under study should be set aside and we should review the immediate experience of it as a possibility for finding new meanings or an enhancement of a current meaning (Crotty, 1998; Husserl, 1970; Introna \& Ilharco, 2004; Manen, 2002).

In this study of the CRM phenomenon, a Heideggerian phenomenology has been followed. To Heidegger, the phenomenon shows some appearances, although the essence of it is behind such appearances.

Heidegger, in contrast to Husserl's (1970) phenomenology, claims that it is not possible to acquire adequate evidence and complete freedom of prejudice when dealing with a phenomenon. Prejudice and preconceptions do not lead to false interpretations of the world, but are instead necessary conditions to form a background for interpretation (Winograd \& Flores, 1987). To Heidegger, there are no such things as wrong or right interpretations; life is always interpreting. Phenomenology, thus, is hermeneutic, which means, it is interpretative (Dreyfus, 1994; Gadamer, 1992).

Hermeneutics can be considered as a theory or philosophy of the interpretation of meaning. It is primarily concerned with the meaning of a text or text-analogue. A text-analogue is anything that can be treated as a text, such as an event, an action, an organization or a culture, and even an Information System (Boland, 2002; Myers, 2004). The origin of hermeneutics lies in the concern with interpreting ancient religious texts (Boland, 2002; Klein \& Myers, 1999; Myers, 2004), but its main objective is "human understanding: understanding what people say and do, and why" (Myers, 2004, p. 103).

According to Dreyfus (1994), Heidegger proposes a hermeneutics of everydayness that involves the understanding of everyday practices and discourse, but in a deep sense, since the fundamental aspects of our existence hide their structure behind common sense. Researchers have to be suspicious and try to get a deeper and a clearer understanding of them. Researchers must be prepared to revise 
radically their traditional accounts of objects, subjects, language, space, truth, reality, time, etc, on the basis of the phenomena revealed by their interpretation. According to these propositions, Heidegger (in the initial phase of his work) claims a phenomenology of suspicion.

This philosophical and methodological approach indicates the necessity of approaching organizational phenomena by questioning the models and concepts taken -for granted about them, and to pay attention to the unexpressed aspects of organizational life, observing the flow of events and considering that "the everyday apparitions should instead be looked at as symptoms, pointers to an organizational phenomenon that does not manifest itself directly. Both appearances and apparitions are generated by the underlying phenomenon to be unveiled" (Ciborra, 2002, p. 178).

According to Manen (2002) phenomenological studies cannot be formalized into a series of technical procedures. However, a variety of activities may be identified that can help in making a phenomenological inquiry. There are two main types of activities: empirical and reflective methods:

Empirical inquiry activities aim to explore the range and varieties of pre-reflective experiential material that is appropriate for the phenomenon under study. Reflective inquiry activities aim to interpret the aspects of meaning or meaningfulness that are associated with this phenomenon (Manen, 2002, p. 1).

Considering empirical activities, this study is based on previous works (both in consultancy and in academic research) by the authors, about CRM. This previous empirical experience has been considered and the following reflective phenomenological methods have been applied (Manen, 2002):

Conceptual analysis - this is the process of examining a complex conceptual or linguistic entity into its most basic semantic constituents, considering that the meaning of a concept lies largely in its usage. In this study, the different definitions and concepts about CRM presented in the literature were revisited, as well as the ideas related to this concept, including: relationship, trust, communication, etc. (see next section, especially item The Meaning of Relationship).

Etymological reflection - Frequently the words that are used to refer to a phenomenon have lost some of their original meaning. Being attentive to the etymological origins of words may help the researchers to understand the origins and the essence of concepts that are usually taken for granted. In this sense the origins of the term relationship have been analyzed, as well as its meaning and all that a relationship implies (see next section, especially item The Meaning of Relationship).

- Collaborative reflective discussions - this type of discussion is helpful in generating deeper insights and understanding about a concept. Themes and insights can be examined, articulated, reinterpreted or reformulated. The author's empirical experiences, both in consultancy and in academic research in the field of CRM and Information Technology applied in organizational processes have been discussed, as well as the concrete observations of unsuccessful experiences of CRM adoption. The results of these discussions are presented throughout the article, but especially in Sections Discussion and Final Comments.

It is important to clarify that this phenomenological approach is related to an interpretative research paradigm. Following a Heideggerian phenomenology, the study is not free of biases, in the sense that even the choice of the subject of study is conditioned by the previous personal experiences of the authors, which includes a set of values and beliefs. This has to be considered as a limitation.

This methodological approach was considered since it is valid for the purposes of this particular article in proposing a critical and reflective revision of CRM. It does not follow the conditions of a positivist study. This paper aims to encourage reflection and indicate themes for future research that can be conducted later on according to different (including positivist) perspectives and methodologies. This limited scope has to be considered as another limitation of this particular study. 


\section{SEARCHING FOR THE ESSENCE OF CRM}

Following the methodology as explained above, this section presents a conceptual analysis based on a literature review, revisiting and examining the different definitions and concepts of CRM.

\section{The Multiple Definitions of CRM}

Throughout a literature review, by authors such as Payne and Frow (2005) and Ngai (2005), different CRM definitions can be found. As consulting IT firms play a relevant role in the dissemination of CRM ideas, it is relevant to consider the way vendors define CRM as well.

By analyzing the different CRM definitions, it is possible to conclude that they can be split into three main CRM approaches. These three different perspectives on CRM are classified in Table 1:

CRM as a philosophy of doing businesses, which has to be considered above any kind of strategy or tool. A CRM philosophy is related to a customer-oriented culture keen on building and cultivating long-term relationships with customers;

CRM as a strategy, as an organizational strategy that will drive functional plans and actions toward building relationships with customers;

. CRM as a tool, focused on the role of IT being used to gather, analyze and apply data to build and manage relationships with customers.

Table 1: Different CRM Approaches

\begin{tabular}{|l|l|l|}
\hline \multicolumn{1}{|c|}{ Approach } & \multicolumn{1}{|c|}{ Definition } & \multicolumn{1}{c|}{ Source } \\
\hline \multirow{4}{*}{$\begin{array}{l}\text { CRM as } \\
\text { Philosophy }\end{array}$} & $\begin{array}{l}\text { CRM refers to the idea that the most effective way to achieve } \\
\text { loyalty is by proactively seeking to build and maintain long- } \\
\text { term relationships with customers. }\end{array}$ & $\begin{array}{l}\text { Zablah, Bellenger } \\
\text { and Johnston (2004) }\end{array}$ \\
\cline { 2 - 3 } & $\begin{array}{l}\text { A philosophy of doing business that will affect the entire } \\
\text { enterprise. }\end{array}$ & Newell (2003) \\
\hline \multirow{5}{*}{$\begin{array}{l}\text { CRM as } \\
\text { Strategy }\end{array}$} & $\begin{array}{l}\text { Resources destined for relationship building and maintenance } \\
\text { efforts should be allocated based on customers' lifetime value } \\
\text { to the firm. }\end{array}$ & $\begin{array}{l}\text { Zikmund, Mcleod } \\
\text { and Gilbert (2003) }\end{array}$ \\
\cline { 2 - 3 } & $\begin{array}{l}\text { CRM is the strategic use of information, processes, } \\
\text { technology, and people to manage the customer's relationship } \\
\text { with a company across the whole customer life cycle. }\end{array}$ & $\begin{array}{l}\text { Kincaid (2003, p. } \\
\text { 41) }\end{array}$ \\
\cline { 2 - 3 } & $\begin{array}{l}\text { CRM is a comprehensive strategy and process of acquiring, } \\
\text { retaining, and partnering with selective customers to create } \\
\text { superior value for the company and the customer. }\end{array}$ & $\begin{array}{l}\text { Parvatiyar and Sheth } \\
\text { (2001, p. 5) }\end{array}$ \\
\cline { 2 - 3 } & $\begin{array}{l}\text { Resources destined for relationship building and maintenance } \\
\text { efforts should be allocated based on customers' lifetime value } \\
\text { to the firm. }\end{array}$ & Ryals (2003) \\
\hline
\end{tabular}




\section{(conclusion) \\ Table 1: Different CRM Approaches}

\begin{tabular}{|c|c|c|}
\hline Approach & Definition & Source \\
\hline \multirow{5}{*}{$\begin{array}{l}\text { CRM as } \\
\text { Technological } \\
\text { Tool }\end{array}$} & $\begin{array}{l}\text { Software, tools and systems can be viewed as technology- } \\
\text { based applications to support the CRM process. They include } \\
\text { database capabilities to collect and analyze customer } \\
\text { information using statistical techniques such as data mining. }\end{array}$ & Ngai (2005, p. 588) \\
\hline & $\begin{array}{l}\text { "Leveraging technology to engage individual customers in a } \\
\text { meaningful dialogue so that firms can customize their } \\
\text { products and services to attract, develop, and retain } \\
\text { customers". }\end{array}$ & $\begin{array}{l}\text { Campbell (2003, p. } \\
375)\end{array}$ \\
\hline & $\begin{array}{l}\text { CRM is a macro level process that subsumes numerous sub- } \\
\text { processes, such as prospect identification and customer } \\
\text { knowledge creation. }\end{array}$ & $\begin{array}{l}\text { Srevastava, Shervani } \\
\text { and Fahey (1999) }\end{array}$ \\
\hline & $\begin{array}{l}\text { Technology does play a substantial role in CRM efforts by, } \\
\text { among other things, seamlessly linking front and back office } \\
\text { functions to provide for the efficient and defective } \\
\text { management of interactions across different customer touch- } \\
\text { points. (...) thus, it seems that both over and underestimating } \\
\text { the role that technology plays in CRM initiatives can have } \\
\text { detrimental effects on firms' relationship management efforts. }\end{array}$ & $\begin{array}{l}\text { Zablah et al. (2004, } \\
\text { p. 479) }\end{array}$ \\
\hline & $\begin{array}{l}\text { "To some executives, customer relationship management } \\
\text { (CRM) is a technology or software solution that helps track } \\
\text { data and information about customers to enable better } \\
\text { customer service". }\end{array}$ & $\begin{array}{l}\text { Peppers and Rogers } \\
(2004, \text { p. } 5)\end{array}$ \\
\hline
\end{tabular}

Source: created by the authors based on a literature review.

Considering the last approach (CRM as a technological tool), CRM is frequently viewed as an information system (commonly a software package) or a group of tools (hardware and software) such as powerful databases, data mining tools, sales force automation applications, call centre technologies, web systems (such as portals), among others, applied in helping firms to identify customers, to support market segmentation, interaction with customers and personalization of products and services (Peppers \& Rogers, 1997).

According to this business logic, the main idea is to use IT to develop, for instance, target marketing, saving money with untargeted, wasteful promotional campaigns. Another usual goal is to reduce the costs of interacting with/attending clients, such as in the current widespread diffused call centers. All the above listed IT tools, especially powerful database technologies, can also be used to support upselling and cross-selling tactics (O'Malley \& Mitussis, 2002; Peppers \& Rogers, 1997). Another common application of IT tools is for calculating the customer's life-time value (Ryals \& Payne, 2001).

Nevertheless, several authors agree that without a CRM philosophy or strategy, the application of IT for CRM efforts is meaningless or at least incomplete (Gummesson, 1998; Langerak \& Verhoef, 2003; Newell, 2003; O’Malley \& Mitussis, 2002; Payne, 2006; Peppers \& Rogers, 2004).

The CRM as strategy approach is related to a formal and deliberated plan and actions to articulate processes, people, structure and technology to acquire, select and retain customers with a high lifetime value to the firm, independently of the specific IT applied to support this strategy.

In its turn, the CRM as a philosophy approach goes beyond a deliberate strategy or tool application. It is related to positive attitudes towards all kinds of stakeholders. It involves a deep understanding of what relationship means and of all implications related to establishing a relationship (such as trust, common objectives, increasing value on both sides, etc.). 
According to this type of analysis, this philosophy is supposed to guide organizational and functional strategies (CRM as strategy); these strategies, in their turn, would have to guide IT applications for CRM (CRM as a tool) - Figure 1.

Figure 1: Links between Different CRM Approaches

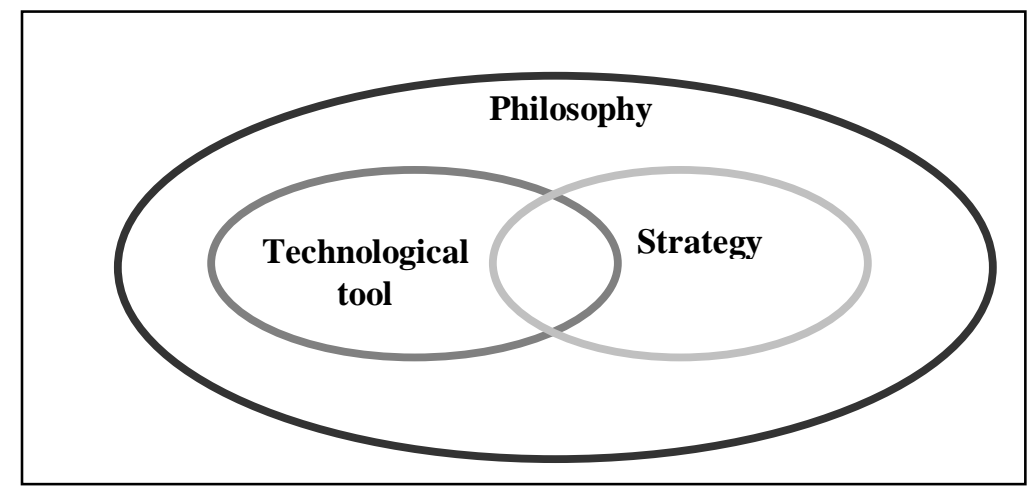

Source: created by the authors based on a literature review.

Considering CRM as philosophy is the background for any strategy and IT application, it is possible to have a better understanding of what it really means. For this purpose, the focus of the next section is the essence of the concept of CRM, by illuminating the understanding of the very concept of relationship.

\section{The Meaning of Relationship}

In order to understand the essence of CRM, the meaning of the concept of relationship has to be discussed. The section begins by analyzing the origins of this term, making an etymological reflection, as mentioned in the methodology section.

The term relationship comes from the Latin relatio, relatio + onis, which means carrying back, bringing back, also with the meaning of repetition and reference, resemblance, repayment (Random, 1999; Simpson, 1971; Simpson \& Weiner, 2000; Woodhouse, 1972). Relation has the meaning of dependence between two things, liaison, friendship, to know each other, intimacy, reciprocity, political, commercial and cultural mutual interests.

By analyzing these different meanings of the term, it can be concluded that a relationship implies commitment, duties, mutual understanding and goals. In this line of thought, Ford, Gadde, Hakansson and Snehota (2003, p. 37) claim that a company's relationship with its customers, suppliers and others is an asset for the company but is also a burden for it to carry.

By exploring the literature, a set of conditions and implications that a relationship demands can be pointed out:

. Mutual knowledge - First of all, a relationship implies mutuality. In order for any state of affairs to be considered a relationship, both parties have to participate in and be aware of the existence of the relationship. This means it must be inherently a two-way relation in nature. For instance, a customer can have a great deal of affection for a brand all by herself but, a relationship between the customer and the brand can only be said to exist if the brand is also aware of the individual customer's existence (Peppers \& Rogers, 2004, p. 36).

- Symmetry - This is a combination of many relationship elements, including information sharing, dependence, and power. Symmetric relationships are more stable than asymmetric ones, because asymmetry undermines the balance of power and creates motivation for the stronger party to take 
advantage of the weaker party, especially in difficult economic conditions. "(...) Symmetric interdependence exists when the relationship members are equally dependent on each other" (Britton \& Rose, 2004, p. 49).

. Long term orientation - As the very origin of the term relationship indicates, it has to have a long term orientation, with the idea of repetition. It demands that sometimes one of the sides will have to give up some current interests to sustain the long term relationship as a whole.

- Communication - Ford et al. (2003) emphasize the importance of two-way communication that "enables the parties to become aware of each other and learn (and teach) each other about what they stand for, what they need from the relationship and what they can offer to it" (Ford et al., 2003, p. 39). Communication is interpersonal and dependant upon a social context.

. Mutual benefits and satisfaction - Another characteristic of a relationship is that satisfied customers are generally more inclined to remain in the relationship. While it is accepted that there exists a positive relationship between customer satisfaction and customer loyalty, the relationship between customer satisfaction and the duration of the relationship is more complex (Britton \& Rose, 2004, p. 46). According to O'Malley and Mitussis (2002), the idea that both parties can derive value from a relationship requires consideration of the motivations, expectations, costs and rewards involved for both organizations and customers in a relationship.

Mutual trust and fairness - While relationship quality is a somewhat subjective term, it is plausible to measure relationship quality based on the levels of trust, commitment, and the ability to solve conflicts effectively. The higher the levels of these contributors, the greater the quality of the relationship: “(...) Trust is defined as one party's confidence in the other relationship member's reliability, durability, and integrity, and the belief that its actions are in the best interest of and will produce positive outcomes for the trusting party" (Britton \& Rose, 2004, p. 43).

- Mutual learning - In order for a company to develop a relationship with a customer, the learning relationship process is crucial. The more the organization is prepared to learn from a customer in a close relationship, the more the company can provide exactly what the customer wants and the more the customer will invest in the relationship. The opposite way is also true: the customer has to be involved in learning the way the company works and evolves its practices, services, products, channels for contact, etc.

- Mutual commitment and efforts from both parties - To develop an efficient relationship, both sides have to commit themselves and invest efforts, such as "time spent developing contacts with the counterpart, or developing the offering or introducing different equipment or working practices" (Ford et al., 2003, p. 40).

Uniqueness - According to Ford et al. (2003, p. 38) "there is no such thing as a "standard relationship"'; each relationship is unique in its content, its dynamics, how it evolves, how it affects the parties involved, and what it requires for each of them to succeed. Anderson and Jap (2005) say that sometimes it is necessary to make unique adaptations or investments to support a relationship.

Freedom - Ford et al. (2003, p. 59) remind us that all relationships are unruly: developing a relationship with someone means giving up some freedom. So unruliness is an essential aspect of any relationship, because it can never be fully controlled by one party.

. Uncertainty - since relationships have a time dimension, they have a future that is uncertain and a history whose interpretation is subjective and can be changed (Ford et al., 2003). Their development depends upon how the parties involved view each other's capabilities and motives and how they interpret their own actions and those of others. The interpretation can change throughout new experiences. 


\section{DISCUSSION - FROM PHILOSOPHY TO PRACTICE}

After exploring the different definitions of CRM and the meaning and implications of a relationship, a conclusion can be drawn that the very concept of CRM has to be revisited.

Since a true relationship is based on emotions and implies elements such as mutual knowledge, some level of symmetry, long term orientation, communication, mutual benefits and satisfaction, mutual trust and fairness, mutual learning, mutual commitment, investments and efforts from both sides, uniqueness and, above all, freedom and uncertainty, it is important to question the very existence of a true relationship between a company and its customers.

Each one of these relationship characteristics could be analyzed, and for each one of them many obstacles and challenges could be found, considering a relationship between one organization and its customers as well as the role of IT in supporting a relationship.

Starting with the notion of mutual knowledge, the usual difficulties in knowing and gathering personal information about clients can be considered. It is not only an IT challenge; it also involves privacy and ethical issues. It is intimately related to the notion of symmetry, in the sense of information sharing, which is difficult for both parties - for the customer to access information about the firm and the firm to access information about the customer.

Considering economic theories such as the agency theory (Jensen \& Meckling, 1976), they remind us of the difficulties and even the impossibility of having informational asymmetry between agents with different and sometimes incongruent interests within an organization. Extrapolating this power game beyond the organizational frontiers, it is easy to see how hard it would be to have asymmetry in a relationship with clients, especially in a capitalist environment.

The same rationality is valid when the idea of a win-win approach for a full and lasting relationship is considered. According to the usual managerial logic, the background is always the search for efficiency, cost reduction and profit maximizing, which is frequently obtained at the cost of maintaining long term relationships.

On the other hand, according to the theory of consumer behavior (Williamson, 2002) customers will attempt to maximize utility for themselves, frequently without caring about the organization or loyalty issues at all. If self-interest, opportunism and lack of goal convergence even exist within a company, it is very difficult to establish a win-win relationship between the firms and their customers.

Considering this economic rationality for analyzing some IT tool for CRM, it is possible to see these divergent interests in practice. For instance, call centers are frequently associated with CRM, while in practice something more impersonal, cost-reduction oriented than this kind of tool is hardly possible to find. Uniqueness (a condition for a relationship) is expensive. When a firm imposes a cold, impersonal, machine-guided interface in its interaction with customers, all the assumptions of freedom, uniqueness and caring, go away.

As another empirical example, where is the respect for freedom when a company uses IT to monitor their customers to detect changes in the level of consumption or to impose up-selling or cross-selling promotions? Usually these practices carry out massive efforts to lock-in the customer, even throughout economic penalties or pressure. CRM IT tools are frequently applied to aid this kind of action, for instance, via data mining applications or up-selling and cross-selling engines inside CRM systems.

Going further and considering not only an economic perspective, but a social one, the complexity of power, ethical and emotional elements standing on the background of the idea of relationship can be easily seen. Taking, for instance, the notion of mutual trust, it is possible to see how fragile the ideal of establishing a deep, lasting, intimate relationship with clients in a world driven by contracts is (Williamson, 2002). 
Britton and Rose (2004) compare personal and business relationships, claiming that they have many similarities. They say that the benefits of a successful marriage include companionship, intimacy, personal growth, shared finances and shared household responsibilities, and must be perceived to provide value for both relationship members in order to last.

However, considering the usual business logic, is it possible that this kind of relationship exists between a firm and its customers?

It is relevant to question the very possibility of the existence of a true relationship between them, in the complete sense of the term, with all the economic, social and ethical implications that this kind of relationship implies. Some authors help us to support this claim. To Dowling and Uncles (1997), usually a relationship program's goals are extremely clear in emphasizing companies' profitability. They point out that companies wish to maintain and augment their sales and profit levels, to increase customer loyalty and value and to induce customers to buy. The authors wonder how this can be called a relationship, since the companies' intention is one-sided. Barnes (2004, p. 51) explains that:

(...) After all, if you were to ask a friend or even a stranger to tell you about her relationships, it is most likely that the conversation would center on relationships with family, friends, neighbors, workmates and team members. Few, I would suspect, would begin by talking abut Marriott Hotels, United Airlines, Coke or Wal-Mart. Relationships are intensely personal concepts. In fact, some people have great difficulty associating the term relationship with the commercial interaction between a company and its customers.

As the author argues, relationships are based, at the end of the day, in emotional ties; they are so much deeper than a functional connection. They are characterized by dimensions such as mutual respect, caring, empathy, warmth, social support and effective two-way communication (Barnes, 2004). He claims that a large portion of what contributes to long-term satisfaction and loyalty has absolutely nothing to do with products or prices. It has a great deal more to do with how the customer is treated, what he or she goes through and ultimately how he or she feels about dealing with a company.

Going further, Dowling (2001) criticizes the relationship marketing idea in all kinds of company sectors since often the customer does not want to develop a relationship with a company.

Since a true relationship demands a lot of effort from both parties, it must have a strong motivational drive. Dowling (2001) believes that there exist at least three kinds of relations between a customer and a company: a close relationship, a relationship just to maintain a dialogue and a non-existent relationship. The author highlights that in the last case, customers can be very loyal, but do not desire to talk with the company, and this position needs to be respected.

Moreover, in order to develop a good relationship with customers, the internal relationships within a firm have to have a sustainable basis. To obtain a unified view of customers, different sectors have to exchange information about all processes and issues that involve them (Payne, 2006). However, over the course of most companies' management history, the organizational chart has suggested that the boundaries between the different sectors have been rigid. These fixed barriers had resulted in different structures, languages, control systems, symbols, stories, paradigms, etc. in each sector (Payne, 2006).

As mentioned above, there are different agents, interests and power games within the organization, while a CRM philosophy would demand putting the customer above all these differences. Bentum and Stone (2006, p. 29) argue how difficult it is to have a CRM culture diffused all over the organization, since the organization itself is formed by subcultures, and each one of them views the customer through different perspectives.

The information integration supported by the use of CRM IT tools has an essential role to play in this sense, but it cannot stand alone to promote a true and deep integration towards a customercentered organization. A true CRM culture requires a sophisticated approach to integrate different 
subcultures, and demands continuous leadership at all organizational levels (Bentum \& Stone, 2006, p. 29).

Even considering that some level or kind of relationship between a company and its customers is established, ranging from a continuum of a very functional relationship to a very emotional one (Barnes, 2004, p. 53), it is also important to consider that the total management of such a relationship is not possible.

To manage a relationship requires a very arbitrary and unilateral attitude, which is in opposition to the very meaning of relationship. Barnes $(2004$, p. 53) also criticizes the notion of relationship management since successful relationships are bidirectional. Much of what is labeled as customer relationship management in current business vocabulary is definitely one-sided (Barnes, 2004).

As mentioned in the call center example, CRM IT tools can be very hindering if used without a clear understanding of relationships. However, this kind of reflection rarely occurs in practice. It is important to consider that in most cases, CRM software has been pushed onto the market by IT consulting firms and software houses, following the Internet and ERP systems boom in late 90's.

Some previously non customer-oriented companies that acquired a CRM system, either as a result of the influence of IT consulting or competitors, have faced difficulties in CRM initiatives. Some of these problems are outlined below:

(1) First of all, managers have problems with proving the importance and return on CRM investment to top managers. Frequently, they solve this problem by manipulating the metrics and financial values of taxes involved. CRM initiatives require a commitment from the top management (Ryals \& Knox, 2001) and, generally, it is only possible if the managers perceive a favorable Return on Investment [ROI].

(2) The scope of a CRM project is a crucial decision. As CRM is a complex project that involves all departments in a company, firms usually try to adopt CRM on a large scale. Many of them fail due to few resources and little energy for a careful CRM adoption in all departments at the same time. As a result of the failure of the first trial, project members sometimes propose a second trial, with a narrow scope in the early stages, followed by widening the dimensions of the project. Several authors (Chalmeta, 2006; Goodhue, Wixom, \& Watson, 2002; Peppers \& Rogers, 2004) claim that companies should not implement all kinds of IT at the same time, adopting instead a progressive policy of IT investment.

(3) CRM tool adoption requires the rethinking of organizational processes. The redesigning of business processes allows companies to integrate customer knowledge into the actual core processes (Raman, Wittmann, \& Rauseo, 2006; Ryals \& Knox, 2001). It is necessary to decide which processes will be changed and whether the CRM package will be customized or not. Some companies do not "waste time" on such a reflection and adopt the software without an exhaustive analysis of the processes. The consequences are dangerous, e.g. information islands, and resistance becomes even stronger. In other cases, companies extremely customize the tool in order to continue with traditional processes, spending a great amount of money, time and effort. The fact is that companies usually do not rethink their processes in the face of a CRM tool adoption.

(4) The integration of various information systems in the organization and previous work with legacy data are relevant issues. The integration of different information systems and knowledge repositories across organizational boundaries make customer data reliable (Peppard, 2000). Frequently, CRM packages do not cover all the information necessary for dealing with customers. The maintenance of several information systems will demand the CRM supplier's knowledge of legacy systems.

(5) Employee resistance to CRM software is a result of the elements discussed above. Training programs are offered to employees, generally in connection with technological issues rather than behavioral aspects related to a CRM philosophy. The technological CRM focus overlaps with the 
attention paid to customers. Employees must receive training programs which cover technological and organizational changes (Raman et al., 2006).

(6) Outsourcing is perceived as a solution for managing activities that are not considered core ones in a company. Following this rationale, call centers and shops are, in many cases, the responsibility of a company's partner. Outsourcing this type of process requires the standardization of procedures and a close relationship between the partners. Call Center employees must work with the same company's values and goals, since, for the customers, they are the company's voice. In practice, this is rarely the case. Call Centers are organized with an economic approach and their strategic value is frequently forgotten.

(7) The policy for evaluating and rewarding employees in a company that has adopted CRM is another crucial issue. The alignment of organizational mission, vision, technology and goals is an important CRM adoption issue (Chalmeta, 2006; Ryals \& Knox, 2001). Frequently, the organizational goals do not reflect departments and employee's goals and metrics. In some companies, sales departments are concerned with selling activities, since they are evaluated and rewarded only according to sales metrics. Due to this fact, sales people they usually think that maintaining a close relationship with customer is not their responsibility. As a result, customers that complain or make suggestions do not receive a satisfactory amount of attention.

Taking the discussion above into consideration, a set of implications for research and practice can be drawn, as indicated in the next and final section.

\section{FINAL COMMENTS: REVISITING tHe CONCEPT OF CRM AND ITS IMPLICATIONS FOR RESEARCH AND PRACTICE}

Considering the previous analysis and discussion, a series of propositions can be drawn which would be useful for researchers and practitioners involved in CRM projects and management.

Regarding practical propositions, it must be considered that, prior to adopting a CRM tool, it is necessary to evaluate whether or not the organization is already oriented by a philosophy of CRM, whether the company is in fact customer-centered, and whether its culture and history show that collective efforts have been made to create and support long-term relations with customers.

Of course, there will be different levels of engagement with CRM's philosophy. In some cases, a series of activities and changes will be necessary in order to prepare the path for CRM implementation. In others, the project must be postponed to avoid the CRM tool becoming an enemy: in the past, some companies had the excuse of not having enough data/information in order to understand and satisfy customers. CRM tools can supply companies with a consistent database, but if the company is not prepared to use this information to provide a good service, the same tool can make this organizational incompetence even more evident to customers.

For instance, some companies create a Relationship Center in the wake of a CRM tool adoption, but it is simply useless because either managers and employees (historically and culturally) are not concerned about customers at all, or the organizational structure is so thin and unprepared that there are not enough qualified people to serve clients properly via the new channels opened by CRM tools, not to mention that resistance to CRM tools can be so intense that a lot of money and effort can be dramatically wasted.

Changes in the organizational structure, levels of empowerment of people dealing with customers, rewarding and evaluation staff systems connected to CRM goals, employees' selection and qualification - all these issues have to be linked to a CRM strategy that also has to support the adoption of a CRM tool. Even if the company is already customer-centered and has a CRM 
philosophy, an isolated CRM tool without process revision, adaptations and involvement of all areas and managers will not be efficient.

Even if the easiest part of this puzzle is considered - the CRM IT standalone tool, the definition of this tool, the data required, the levels and views of access, the scope and context of implementation all these issues must be considered under the notion of cultivation: the technology has to be designed collectively, it has to be constantly revised and adapted according to the way it will actually be hosted by the employees, as well as the customers.

A collaborative design project is essential, involving a multidisciplinary team inside the organization, customers, suppliers and all the stakeholders involved directly or indirectly, with customers.

It is also important to highlight that understanding the meaning of relationship is an essential condition for developing a CRM philosophy that has to guide CRM strategies or, at least, drive the use of IT to support relations with customers. A CRM philosophy implies a high level of commitment, coordination and integration among all members of an organization and beyond, involving even the other actors in the value chain, towards a customer-oriented culture.

In this sense, claiming that companies have to be very critical of the goals that they set for CRM strategies and IT applications is also important. Sometimes a company is seen to have great expectations (such as customer loyalty, increasing profits, etc.) when adopting a CRM IT tool. However, the company is, in fact, embracing a CRM technological approach that goes against any action that could really nurture a lasting relationship with its customers.

Therefore, the expectations for the results of a CRM IT tool adoption must be carefully considered. By understanding the idea of a CRM philosophy and strategy that have to precede this tool adoption, managers have to be very realistic about what to expect in the short and in the long term. Hopefully, the proposed discussion can be useful for this kind of reflection.

Considering implications for academic research, this study proposes some questions and assumptions to be verified via empirical research.

Firstly, it would be important to better understand the correlation between what a company understands as CRM and the true concept of relationship, the company's goals and the company's benefits obtained by adopting a CRM initiative.

It would also be interesting to explore to what degree it is really possible to manage relationships with customers. The research supposition in this case would be that relationships have to be cultivated instead of managed. This supposition is inspired by the concept of cultivation proposed by B. Dahlbom and L. E. Janlert (1996, Computer future. Manuscript received directly from the first author via e-mail). The purpose of this paper is to explore, empirically, the idea that a relationship between a company and its customers is a process that cannot be totally controlled, and is rather a natural process demanding support and monitoring, protection and care. As Barnes (2004, p. 52) claims, customers do not deliberately set out to create relationships with companies: the relationships simply evolve. Relationships take time to develop and must be nurtured. This kind of approach (cultivation) would be interesting as an alternative theoretical basis for studying CRM.

Finally, the paper proposes the analysis of the new technologies that have been developed, such as blogs, social networking and RSS (Really Simple Syndication). The so called Web 2.0 provides opportunities for the emergence of new business approaches related to CRM concepts. It is important to explore the motivation and the basis of the close relationship (1) between companies and customers and (2) customers in the so called Social CRM.

This paper aims to help academics and practitioners think beyond the common meaning of CRM. CRM initiative presupposes more than a technological approach, a strategic action and organizational 
What Lies behind the Concept of Customer Relationship Management? Discussing the Essence of

philosophy. CRM is about a relationship between a company and a customer, and it requires a deep understanding about what each actor is looking for in the establishment of this relationship.

\section{REFERENCES}

Anderson, E., \& Jap, S. D. (2005). The dark side of close relationships. MIT Sloan Management Review, 46(3), 75-82.

Barnes, J. G. (2004). CRM: the customer's view. In D. Peppers \& M. Rogers (Coords.). Managing customer relationships: a strategic framework. Hoboken, NJ: Wiley.

Bentum, R., \& Stone, M. (2006). Customer relationship management and the impact of corporate culture - a European Study. Database Marketing \& Customer Strategy Management, 13(1), 2854.

Boland, R. J. (2002). Information system use as a hermeneutic process. In M. Myers \& D. Avison. (Eds.). Qualitative research in information systems. (pp. 439-464). London: Sage.

Boulding, W., Staelin, R., Ehret, M., \& Johnston, W. J. (2005). A customer relationship management roadmap: what is known, potencial pitfalls, and where to go. Journal of Marketing, 69(4), 155166.

Britton, J. E., \& Rose, J. (2004). Thinking about relationship theory. In D. Peppers \& M. Rogers (Coords.). Managing customer relationships: a strategic framework (pp. 38-50). Hoboken, NJ: Wiley.

Campbell, A. J. (2003). Creating customer knowledge competence: managing customer relationship management programs strategically. Industrial Marketing Management, 32(5), 375-383.

Chalmeta, R. (2006). Methodology for customer relationship management. The Journal of Systems and Software, 79(7), 1015-1024.

Ciborra, C. (2002). The labyrinths of information: challenging the wisdom of systems. New York: Oxford Press.

Crotty, M. (1998). The foundations of social research: meaning and perspective in the research process. London: Sage.

Dowling, G. (2001). The paradox of customer relationships: often less is more. AGSM. Retrieved March 17, 2007, from http://www.agsm.edu.au

Dowling, G., \& Uncles, M. (1997). Do customer loyalty programs really work? Sloan Management Review, 38(4), 71-82.

Dreyfus, H. L. (1994). Being-in-the-world - A commentary on Heidegger's being and time, division I (5th ed.). Boston: MIT Press.

Ford, D., Gadde, L. E., Hakansson, H., \& Snehota, I. (2003). Managing business relationships. Chichester: John Wiley \& Sons.

Gadamer, H. (1992). Philosophical hermeneutics. Berkeley: University of California Press.

Goodhue, D. L., Wixom, B. H., \& Watson, H. J. (2002). Realizing business benefits through CRM: hitting the right target in the right way. MIS Quarterly Executive, 1(2), 79-94. 
Gummesson, E. (1998). Implementation requires a relationship marketing paradigm. Academy of Marketing Science, 26(3), 242-249.

Heidegger, M. (1962). Being and time. San Francisco: HarperSanFrancisco.

Husserl, E. (1970). The crisis of European sciences and transcendental phenomenology: an introduction to phenomenological philosophy. Evanston: Northwestern University Press.

Introna, L. D., \& Ilharco, F. (2004). Phenomenology, screens, and the world: a journey with Husserl and Heidegger into Phenomenology. In J. Mingers \& L. Willcocks (Eds.). Social theory and philosophy for information systems (pp. 56-101). West Sussex: John Wiley \& Sons.

Jensen, M., \& Meckling, W. (1976). Theory of the firm: managerial behaviour, agency costs and ownership structures. Journal of Financial Economics, 3(4), 305-360.

Kincaid, J. W. (2003). Customer relationship management: getting it right!. Upper Saddle River, NJ: Prentice-Hall PTR.

Klein, H. K., \& Myers, M. D. (1999). A set of principles for conducting and evaluating Interpretive field studies in information systems. MIS Quartely, 23(1), 67-94.

Langerak, F., \& Verhoef, P. (2003). Strategically embedding CRM. Business Strategy Review, 14(4), 73-80.

Manen, M. van (2002). Phenomenological inquiry. Retrieved July 29, 2008, from http://www.phenomenologyonline.com/inquiry/9.html

Myers, M. D. (2004). Hermeneutics in information systems research. In J. Mingers \& L. Willcocks (Eds.). Social theory and philosophy for information systems. (pp. 103-128). West Sussex: John Wiley \& Sons.

Natanson, M. (1973). Phenomenology and the social sciences (Vol. 1). Evanston: Northwestern University Press.

Newell, F. (2003). Why CRM doesn't work: how to win by letting customers manage the relationship. Princeton, New Jersey: Bloomberg Press.

Ngai, E. W. T. (2005). Customer relationship management research (1992-2002): an academic literature review and classification. Marketing Intelligence \& Planning, 23(6), 582-605.

O'Malley, L., \& Mitussis, D. (2002). Relationships and technology: strategic implications. Journal of Strategic Marketing, 10(3), 225-238.

Payne, A., \& Frow, P. (2005). A strategic framework for customer relationship management. Journal of Marketing, 69(4), 167-176.

Payne, A. (2006). Handbook of CRM: achieving excellence in customer management. Burlington, MA: Butterworth Heinemann.

Parvatiyar, A. L., \& Sheth, J. N. (2001). Customer relationship management: emerging practice, process, and discipline. Journal of Economic and Social Research, 3(2), 1-34.

Peppard, J. (2000). Customer relationship management (CRM) in financial services. European Management Journal, 18(3), 312-327.

Peppers, D., \& Rogers, M. (1997). Enterprise one to one - tools for competing in the interactive age. New York: Random House. 
What Lies behind the Concept of Customer Relationship Management? Discussing the Essence of

Peppers, D., \& Rogers, M. (2004). Managing customer relationships: a strategic framework. Hoboken, NJ: Wiley.

Raman, P., Wittmann, C. M., \& Rauseo, N. (2006). Leveraging CRM for sales: the role of organizational capabilities in successful CRM implementation. Journal of Personal Selling \& Sales Management, 26(1), 39-53.

Random House. (1999). Random house webster's unabridged dictionary. New York: Author.

Ryals, L. (2003). Making customers pay: measuring and managing customer risk and returns. Journal of Strategic Marketing, 11(3), 165-175.

Ryals, L., \& Knox, S. (2001). Cross-functional issues in the implementation of relationship marketing through customer relationship management. European Management Journal, 19(5), 534-542.

Ryals, L., \& Payne, A. (2001). Customer relationship management in financial services: towards information-enabled relationship marketing. Journal of Strategic Marketing, 9(1), 3-27.

Simpson, D. P. (1971). Cassell's new compact latin-english, english-latin dictionary. New York: Laurel.

Simpson, J. A., \& Weiner, E. S. C. (Orgs). (2000). Oxford English Dictionary (2nd ed). Oxford: Clarendon.

Srevastava, R. K., Shervani, T. A., \& Fahey, L. (1999). Marketing, business processes, and shareholder value: an organizationally embedded view of marketing activities and the discipline of marketing. Journal of Marketing, 63, 168-179.

Williamson, O. E. (2002). The theory of the firm as governance structure: from choice to contract. Journal of Economic Perspectives, 16(3), 171-195. Retrieved March 17, 2007, from http://www.e-jep.org/archive/1603/16030171.pdf

Winograd, T., \& Flores, F. (1987). Understanding computers and cognition: a new foundation for design. Norwood: Addison Wesley.

Woodhouse, S. C. (1972). Handy dictionary of the latin and english languages. New York: David Mckay.

Zablah, A. R., Bellenger, D. N., \& Johnston, W. J. (2004). An evaluation of divergent perspectives on customer relationship management: towards a common understanding of an emerging phenomenon, Industrial Marketing Management, 33(6), 475-489.

Zikmund, W. G., Mcleod, R., Jr., \& Gilbert, F. W. (2003). Customer relationship management integrating marketing strategy and information technology. Hoboken: Wiley. 